\title{
Expedited Site Characterization
}

Characterization, Monitoring, and Sensors Technology Crosscut Program and Subsurface Contaminants Focus Area

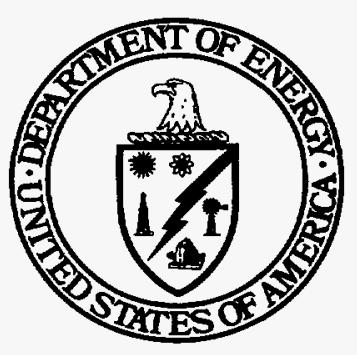

Prepared for

U.S. Department of Energy Office of Environmental Management Office of Science and Technology 
Summary Report

\section{Expedited Site Characterization}

OST Reference \#77

Characterization, Monitoring, and Sensors Technology Crosscut Program and Subsurface Contaminants Focus Area

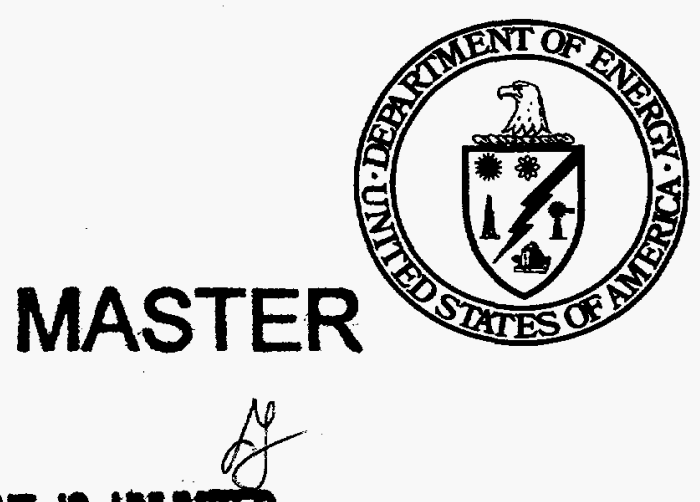

DSTREMTON OF THS DOCUMENT is Unumb 


\section{DISCLAIMER}

This report was prepared as an account of work sponsored by an agency of the United States Government. Neither the United States Government nor any agency thereof, nor any of their employees, make any warranty, express or implied, or assumes any legal liability or responsibility for the accuracy, completeness, or usefulness of any information, apparatus, product, or process disclosed, or represents that its use would not infringe privately owned rights. Reference herein to any specific commercial product, process, or service by trade name, trademark, manufacturer, or otherwise does not necessarily constitute or imply its endorsement, recommendation, or favoring by the United States Government or any agency thereof. The views and opinions of authors expressed herein do not necessarily state or reflect those of the United States Government or any agency thereof. 


\section{DISCLAIMER}

Portions of this document may be illegible in electronic image products. Images are produced from the best available original document. 


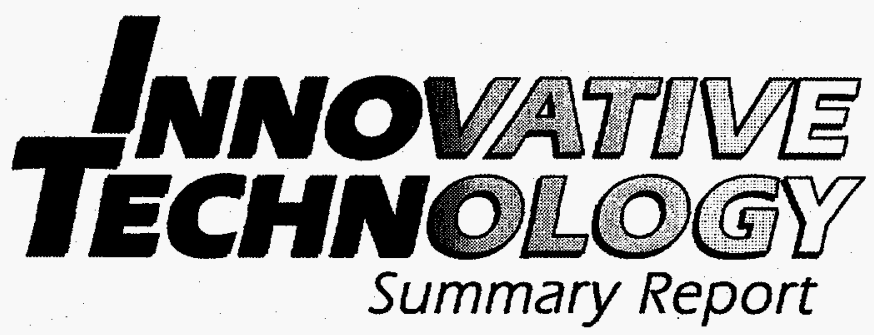

Purpose of this document

Innovative Technology Summary Reports are designed to provide potential users with the information they need to quickly determine if a technology would apply to a particular environmental management problem. They are also designed for readers who may recommend that a technology be considered by prospective users.

Each report describes a technology, system, or process that has been developed and tested with funding from DOE's Office of Science and Technology (OST). A report presents the full range of problems that a technology, system, or process will address and its advantages to the DOE cleanup in terms of system performance, cost, and cleanup effectiveness. Most reports include comparisons to baseline technologies as well as other competing technologies.

Information about commercial availability and technology readiness for implementation is also included. Innovative Technology Summary Reports are intended to provide summary information. References for more detailed information are provided in an appendix.

Efforts have been made to provide key data describing the performance, cost, and regulatory acceptance of the technology. If this information was not available at the time of publication, the omission is noted.

All published Innovative Technology Summary Reports are available on the OST Web site at http://OST.em.doe.gov under "Publications." 
TABLE OF CONTENTS

1 SUMMARY

page 1

2 TECHNOLOGY DESCRIPTION

page 4

3 PERFORMANCE

page 7

4 TECHNOLOGY APPLICABILITY AND ALTERNATIVE TECHNOLOGIES

page 10

$5 \cos T$

page 12

6 REGULATORYIPOLICY ISSUES

page 15

7 LESSONS LEARNED

page 16

APPENDICES

A References 


\section{Technology Summary}

\section{Problem}

In the DOE's Accelerated Clean-up Plan Cost Rollup by Category, over 1.34 billion dollars of the 9.7 billion dollar remedial action budget is allocated to remediation assessment studies. The baseline or traditional method of site characterization uses a phased approach consisting of multiple sampling events with most samples analyzed in the laboratory. Traditional site characterization procedures, conducted in a conservative regulatory environment, are usually effective but can be quite costly and time consuming.

\section{How It Works}

Expedited Site Characterization (ESC) has been developed, demonstrated, and deployed as a new time-saving, cost-effective approach for hazardous waste site investigations. ESC is an alternative approach that effectively shortens the length of the assessment period and may significantly reduce costs at many sites. It is not a specific technology or system but is a methodology for most effectively conducting a site characterization.

The principal elements of ESC are:

- a field investigation conducted by an integrated team of experienced professionals working in the field at the same time,

- analysis, integration and initial validation of the characterization data as they are obtained in the field,

- a dynamic work plan that enables the team to take advantage of new insights from recent data to adjust the work plan in the field.

The ESC methodology emphasizes the delineation of the hydrogeologic framework of the potentially contaminated site, followed by the delineation of the contaminant pathways and contaminant distribution, and the selection of the most effective measurement technologies. Explicit in the process is direct communication with regulators and stakeholders.

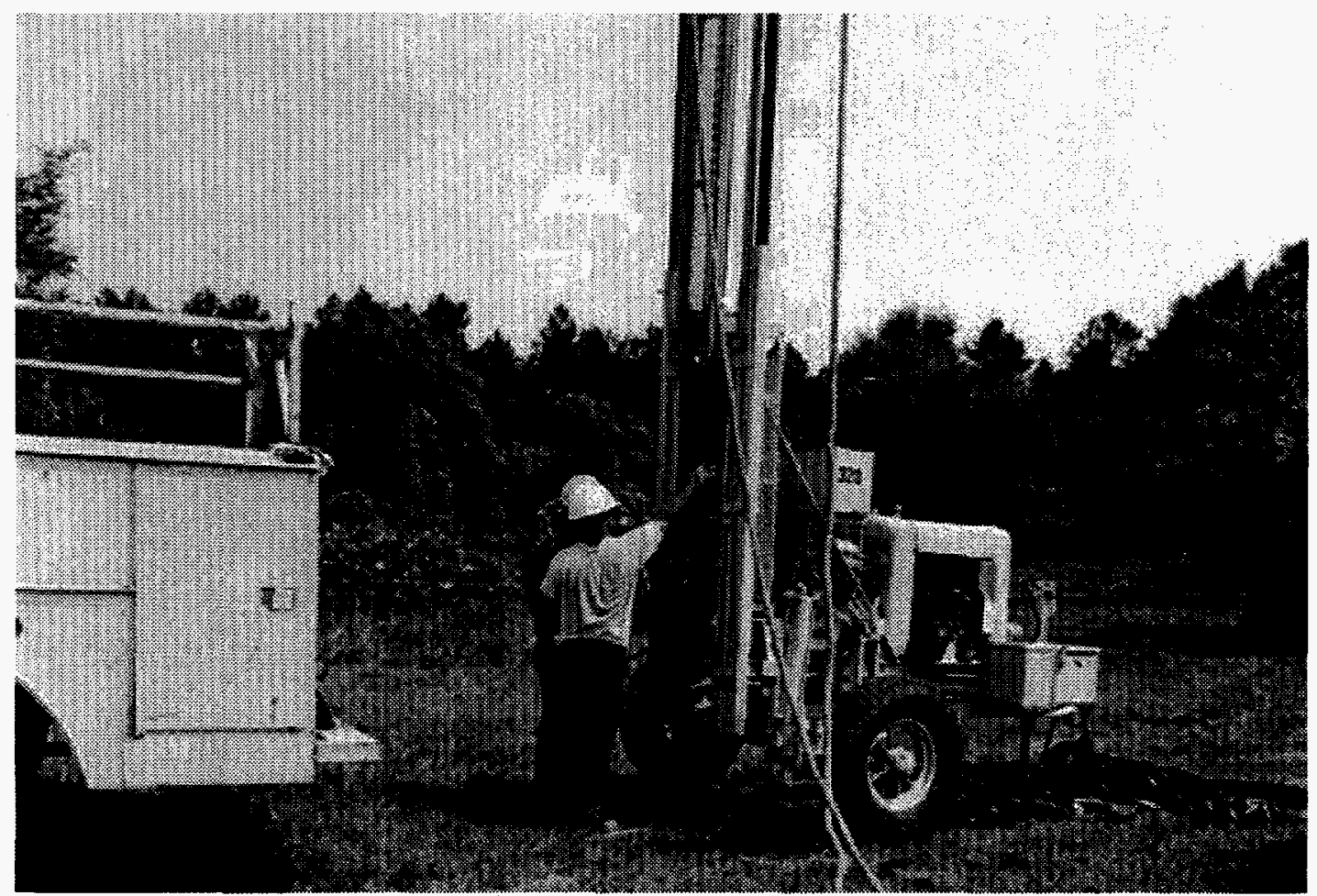

Figure 1. Immediate data analyses are completed using field mobile equipment as shown here at the Savannah River Site. 


\section{Potential Markets}

Generally, the ESC methodology is most cost-effectively applied for:

- large-scale projects including

$\checkmark$ CERCLA (Comprehensive Environmental Response, Compensation and Liability Act, i.e., Superfund) remedial investigations (RI/FS)

$\checkmark$ RCRA (Resource Conservation and Recovery Act) facility investigations (RFI, CMS).

- other contaminated sites where the ESC process can be reasonably expected to reduce time and cost of site characterization when compared with traditional approaches.

\section{Advantages over the Baseline}

The advantages of ESC over traditional methods include:

- use of a wider variety of measurement methods

$\checkmark$ ESC investigations employ a diverse set of measurement techniques, with less reliance on traditional monitoring well data,

$\checkmark$ ESC investigations use more than one measurement to prove or validate each essential feature of the conceptual model,

$\checkmark$ ESC investigations employ innovative technologies where cost savings or data quality are improved.

- an improved rate of data integration; data are continuously analyzed and integrated into the conceptual model; the model evolves both during and between phases.

- a flexible, dynamic work plan that allows newly acquired data to improve the conceptual model, while impacting and optimizing subsequent characterization activities immediately (hours to days).

- potential cost savings are due to many factors

$\vartheta$ reduction in the number of data samples collected,

$\checkmark$ reduction in the number of monitoring wells installed,

$\checkmark$ reduction in the time required to complete assessment,

$\checkmark$ improved assessment accuracy, and

$\diamond$ results that are more credible with regulators.

The target for DOE characterization cost savings in the 2006 Plan budget is $\$ 1.34$ billion. If the Pantex ESC example documented in this report is representative, then its 50\% savings translates into possible DOE complex-wide savings of $\$ 600-700$ million through 2006.

\section{Demonstration Summary}

This report covers demonstrations that took place between 1989 and 1996.

- ESC methodology has been applied to a number of hazardous wastes sites within

$\checkmark$ the DOE complex (the Pantex Weapons Facility in Amarillo TX, the SLAPS Uranium Processing Site in St. Louis MO, the Savannah River Site in Aiken SC, the Central Nevada Test Area, the Painesville FUSRAP Site in Ohio),

$\checkmark$ at DoD facilities (Navy and Air Force),

$\diamond \quad$ at USDI (BLM) and USDA facilities,

$\diamond$ and at commercial facilities in the U.S.and in Poland.

- ESC has been used to

$\checkmark$ delineate contaminant plumes,

$\checkmark$ verify hydrogeological site models,

$\checkmark$ delineate hydrologic systems under CERCLA RI, RCRA RFI, UMTRA, FUSRAP, and state regulatory programs at landfills, petroleum release sites, radioactively contaminated sites, gas manufacturing plants, and grain storage facilities. 
- ESC projects have

0 included evaluation of pre-existing data and incorporation into expedited characterization efforts in the field,

$\checkmark$ generated technically defensible explanations of issues,

$\checkmark$ generated new types of data to assist with site model generation,

$\diamond$ improved plume delineation and identified new aquitards,

$\checkmark$ characterized sites for rapid closure (no further action) saving significant money.

- DOE's CMST-CP funded development of an ASTM Guide for Expedited Site Characterization of Hazardous Waste Sites. The guide documents the implementation of ESC at DOE sites and is an excellent introduction to common sense, cost-effective characterization. This guide is available from ASTM, 1916 Race St., Philadelphia, PA 19103, 2152995480.

- ESC permitting has been accomplished on a case by case basis; several regulators in states and EPA regions where ESC has been applied have expressed willingness to discuss ESC with regulators in states where ESC is being proposed. ESC is being evaluated by the Interstate Technology and Regulatory Cooperation Working Group (ITRC) to expedite multi-state acceptance by regulators.

\section{CONTACTS}

Technical

Jacqueline Burton, Argonne National Laboratories, 630252 8795, jburton@anl.gov

Tom Starke, Los Alamos National Laboratory, 505-667-6639, tps@lanl.gov

Al Bevolo, Ames Laboratory, 515294 5414, bevolo@ameslab.gov

\section{Management}

Charles Nalezny, Office of Science and Technology, Characterization, Monitoring, and Sensor Technology Crosscut, 301-902-1742

Dirk Schmidhofer, DOE-NV, 702-295-0159

\section{Other}

All published Innovative Technology Summary Reports are available at http://em-50.em.doe.gov. The Technology Management System, also available through the EM50 Web Site, provides information about OST programs, technologies, and problems.

The OST reference \# for Expedited Site Characterization is 77. 


\section{TECHNOLOGY DESCRIPTION}

\section{Introduction/Background}

Site characterization is an investigative process for developing an understanding of the extent and environmental impacts of contamination sufficient to assess the risk to humans and the environment. ESC is an alternative approach that shortens the assessment period and significantly reduces costs. It is not a specific technology or system but a methodology or approach.

- The ESC methodology emphasizes the delineation of the hydrogeologic framework of the potentially contaminated site, followed by use of that framework to guide the delineation of the contaminant pathways and contaminant distribution.

- ESC also emphasizes the selection of the most effective measurement technologies.

- The site understanding, or conceptual model, becomes the basis for determining the necessity of site remediation. Critical parameters for the design and optimization of the remedial system are also measured during site characterization.

\section{Process Definition}

Each site characterization is affected by unique aspects of the contaminated site, the regulatory perspective, and the capabilities of the characterization team. The ESC process has ten steps.

\section{Step 1: Team Formation}

A team of seasoned professionals is formed.

- The team is organized into a core technical team and project team. The core technical team consists of three to five experienced professionals who are knowledgeable of hydrologic, geologic, and contaminant chemistry systems. They plan, organize, and direct the investigation and are part of the assessment until it is completed. The core technical team leader is responsible for the overall conduct of the investigation. The actual measurements, data analysis, and support activities are accomplished by a larger project team. Project team members are part of the assessment only for as long as necessary to accomplish their specific activities.

- Members of the project team are selected from technical disciplines that are needed to analyze and integrate new data (for example, geology, geochemistry, geophysics, hydrology, computer science, contaminant transport, ground water modeling, risk analysis, regulatory compliance, health/safety, QA/QC, and analytical chemistry).

\section{Step 2: Critical Evaluation of Existing Data and Development of an Initial Conceptual Model}

The ESC team compiles and evaluates existing data to guide development of the initial conceptual model. Data inconsistencies and conflict are highlighted. A numeric quality level is assigned to all existing data. Some data are processed or reinterpreted if necessary. Data are integrated into an archive and referenced to the coordinate grid.

\section{Step 3: Initial Site Visit: Meetings with Regulators and Site Owners}

As a group, the core technical team visits the field site and walks the ground to meet with the site owner and regulators to discuss the ESC process and the essential issues the investigation should resolve.

- Operational, safety, security, and other site specific constraints relevant to the preparation of the work plan are identified.

- With the site owner and regulators, the ESC team determines essential data needed to address regulatory requirements.

- These discussions typically result in a definition of investigation objectives and identification of issues, for example, the list of analytes.

The site owner often arranges for the Core Technical Team to meet with the public and explain ESC. 


\section{Step 4: Initial Development of the Conceptual Model}

An initial conceptual model that is consistent with available site data and information collected during the initial site visit and that addresses all of the essential features required for risk assessment and remedial action decision making is developed by the ESC team.

- The model is often a set of hypotheses describing the essential features of the site that control the system of pathways between the likely source of contamination and all potential receptors.

\section{Step 5: Identification of Measurement Options}

In the ESC process, all of the measurement techniques that will effectively test the model are identified. ESC uses a diverse set of measurement techniques that test each essential feature of the conceptual model. As ESC measurement data need to be analyzed within hours of being taken, analysis systems (like analytical labs) are usually brought to the field.

\section{Step 6: Formulation of a Dynamic Work Plan}

A dynamic work plan that describes the field investigation plan is developed.

- Dynamic workplans define an area and depth within which the ESC team can adjust measurement parameters without needing to seek additional regulatory approval.

- Every element of an ESC work plan, including data collection and analysis, QAVQC and measurement techniques, is sufficiently robust that the plan can be adjusted without initiating the lengthy process of a formal work plan change.

- The work plan may propose several different measurement and data analysis techniques and the approximate order in which the measurements will be made.

- An ESC investigation will favor techniques that yield analyzed data rapidly, over techniques that require weeks or months to obtain results.

\section{Step 7: Phase I field investigation}

ESC field investigations are short, intense, and productive, and typically require two phases. Timely support from site personnel, logistical support personnel, and the project team is essential, because each element of an ESC investigation is critically dependent on all the other elements.

- In the Phase 1 field investigation, the team returns as a group to the site after the initial site visit.

$\checkmark$ The main purpose of this investigation is to test the accuracy of the initial conceptual model with respect to the system of pathways that contamination could travel from known and potential sources.

$\diamond \quad$ Many simultaneous measurements are made and samples are split to maximize the information yield.

$\checkmark$ Data are analyzed, digitally archived, and integrated into the investigation record as rapidly as possible.

- While in the field the team follows this established procedure:

0 Results are predicted and recorded in lab books before any measurement is made.

$\checkmark$ Measurements are made.

$\checkmark$ Data are analyzed.

$\checkmark$ Data are integrated into the site coordinate system for comparison with other data and the conceptual model.

$\checkmark$ Conceptual model is modified based on measurement results.

$\checkmark$ Subsequent measurements are selected to best test the updated conceptual model.

- The process is repeated until the field investigation successfully meets the established objectives and the conceptual model accurately and convincingly describes all the pathways of concern to regulators and the site owner.

- Although the system of pathways is emphasized, the Phase I field investigation also includes all easily- obtainable measurements and sampling that can contribute to the investigation.

$\diamond$ Surface contamination measurements are often taken in Phase I.

$\checkmark$ Between phases, the results of measurements that could not be quickly analyzed are incorporated into the conceptual model. 


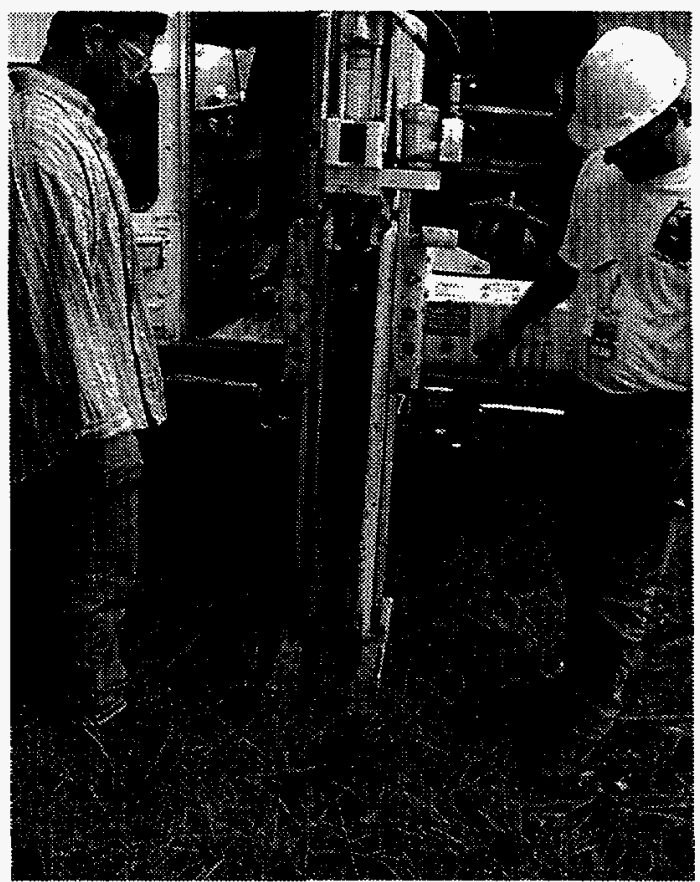

\section{Step 8: Phase II field investigation and initial report}

The Phase II field investigation uses the conceptual model predictions of the system of pathways and contaminant source locations developed in Phase I to locate the contaminant plume. As in the Phase I investigation, the dynamic work plan emphasizes flexibility.

\section{Step 9: Risk Assessment}

Employing appropriate risk methodologies, the proven conceptual model may be used to prepare a risk assessment of the site contamination

\section{Step 10: Final report}

The conceptual model and risk assessment are summarized in an appropriate report format and delivered to the site owner. The team supports the site owner in presenting the report to regulators and the public. 


\section{SECTION 3}

\section{PERFORMANCE}

ESC was first developed by Argonne National Laboratory (ANL) personnel in 1989 to cost-effectively characterize several U. S. Bureau of Land Management landfills in New Mexico. ESC has been applied at many sites by the ANL team and by a team from Ames Laboratory. The following describes the various technology demonstrations/deployments.

\section{Client: USDL/Bureau of Land Management}

Site Type/Size/Depth: 3 landfills ranging in size from $650^{\prime} \times 800^{\prime}$ to $1,000^{\prime} \times 2000^{\prime}$

Location: New Mexico

Date: $1989-1991$

Contaminant: Metals, VOCs, SVOCs, petroleum products

Regulatory Setting: CERCLA RI/FS

Problem or Objectives: Initial data indicated that the migration of contaminants to ground or surface water was likely. ESC Results: ESC showed that the contamination present at the landfill was not migrating deeper that the upper few meters of soil. All 3 landfills were closed with no remediation and no requirement for continued ground water monitoring at a cost of $\$ 300,000$ less than projected.

\section{Client: USDA/Commodity Credit Corporation (CCC)}

Site Type/Size/Depth: 20 former grain storage facilities, $800 \times 1000$ feet up to 23 square miles

Location: Nebraska, Kansas

Date: Ongoing

Contaminants: Carbon tetrachloride, chloroform

Regulatory Setting: CERCLA RI/FS (2 sites from the National Priority List (NPL)), Safe Drinking Water Act (SDWA)

Problem or Objectives: Carbon tetrachloride contamination of drinking water supplies was potentially linked to CCC former operations.

ESC Results: ESC streamlined the RI/FS process and generated technically defensible data for rapid remedial action decision making for $1 / 5$ to $1 / 10$ cost and $1 / 30$ time of conventional methods.

\section{Client: DOE}

Site Type/Size/Depth: Zone 12 Pantex Plant, 1 square mile

Location: Amarillo, TX/ EPA Region VI

Date: 1994-1995

Contaminant: Explosive metals, fuels, chlorinated hydrocarbons

Regulatory Setting: CERCLA RI and RCRA RFI

Problem or Objectives: Previous RI had not generated technically acceptable explanation for contaminant distribution, migration pathways and potential for cross-aquifer contaminant migration.

ESC Results: Re-evaluation, interpretation, and integration of existing (pre-ESC) databases allowed for a streamlined field investigation that generated technically defensible explanation of all issues. The cost impact of this study is discussed in detail in Section 5 of this report.

\section{Client: DoD/Navy}

Site Type/Size/Depth: Closing marine air station, 3 square miles

Location: Western US/Region IX

Date: Ongoing

Contaminant: Fuels, solvents, oils, paints, pesticides

Regulatory Setting: CERCLA RI/FS

Problem or Objectives: Previous RI had not defined aquifer systems (including flow, number of aquifers, etc.), migration pathways, sources, or contaminant distribution.

ESC Results: Phase I investigation delineated hydrologic systems, including flow, number of aquifers, isolation of aquifers, and migration pathways. Phase II presently being conducted by a private sector firm. 
Client: DOD/Air Force

Site Type/Size/Depth: Air Force base, 1,300' x 2,600'

Location: Southwest Region VI

Date: Ongoing

Contaminant: Trichloroethylene (TCE), 1,2-dichloroethene, carbon tetrachloride

Regulatory Setting: CERCLA RI, RCRA RFI

Problem or Objectives: The rapid transfer of ESC approach to a federal agency and contractor for interim corrective action measures selection.

ESC Results: ESC investigation ongoing.

\section{Client: IA Department of Natural Resources}

Site Type/Size/Depth: Former gas manufacturing plant, 3 acres, 50'

Location: Marshalltown, IA, EPA Region VII

Date: 1994 - present

Contaminant: Sixteen polyaromatic hydrocarbons $(\mathrm{PAH})$

Regulatory Setting: State regulatory program

Problem or Objectives: DOE technology demonstration that highlighted immunoassay testing, geophysical methods,

five polyaromatic hydrocarbon soil extraction methods, percussive conductivity logging (ISSTime).

ESC Results: ESC investigation ongoing.

\section{Client: DOE}

Site Type/Size/Depth: SLAPS Uranium Processing Site, 52 acres, 65'

Location: St. Louis, MO, EPA Region VII

Date: 1994

Contaminant: Uranium, thorium, radium, radon isotopes

Regulatory Setting: Uranium Mill Tailing Remediation Act (UMTRA)

Problem or Objectives: Delineate extent of radioactive contaminants in surface soils; evaluate pathways to and extent of karst aquifer beneath uranium-bearing waste piles; determine thickness of aquitard located between two aquifers.

ESC Results: Microgravity and EM surveys were completed to map the thickness of the aquitard and the extent of karsting in the aquifer; geochemical dating of two aquifers was completed. These results assisted with the conceptual model for fate and transport of contaminants from the upper to lower aquifer at this site.

\section{Client: DOE}

Site Type/Size/Depth: Savannah River Site, D-Area Oil Seepage Basin, 10 acres, 65'

Location: South Carolina, EPA Region IV and South Carolina Department of Health and Environmental Control

Date: 1994-1995

Contaminant: Trichloroethylene (TCE), tetrachloroethylene (PCE), vinyl chloride, a-BHC pesticide, $\mathrm{Sb}, \mathrm{Be}, \mathrm{Mn}$ and As metals Regulatory Setting: CERCLA/RI, RCRA/ RFI

Problem or Objectives: Primary objectives were to determine hydrogeology of the site, contaminants of concern, to delineate extent of groundwater contamination; and to assess risk of soil/groundwater contamination.

ESC Results: Contaminant plume would have been missed by originally proposed monitoring well locations; geophysical methods (GPR, EM, borehole logging, percussive electrical conductivity logging, and cone penetrometer) were used to identify two shallow aquitards that control the flow of the 13 contaminants of concern (VOCs, pesticides, and metals). The assessment/remediation schedule was cut by seven months as a result of this project.

\section{Client: Polish government/DOE}

Site Type/Size/Depth: Oil refinery, 15 acres, 60'

Location: Czechowice, Poland

Date: 1996

Contaminant: VOC's, 5 PAHs, RCRA metals

Regulatory Setting: Polish action levels

Problem or Objectives: Demonstration of site characterization technologies.

ESC Results: Demonstrated use of laser-induced fluorescence and $\mathrm{Hg}$ lamp with a cone penetrometer, immunoassay testing, percussive conductivity logging, horizontal drilling and sampling. 


\section{Client: Nevada Field Office/ Off Sites Program/DOE}

Site Type/Size/Depth: Three underground nuclear test sites, 50 acres, 20'

Location: Central Nevada Test Area, Nevada

Date: 1997

Contaminant: Diesel/Motor Oil TPH, Total and hexavalent chromium

Regulatory Setting: Nevada DEP preliminary action levels

Problem or Objectives: Characterize surface and subsurface drilling mud pits and shaker pad debris areas with geophysical and percussive probing techniques and two mobile labs.

ESC Results: Found ten new areas of concern and one new COC; mapped distribution of all COCs at all sites in 22 day field effort.

\section{Client: DOE/FUSRAP}

Site Type/Size/Depth: 52 acres of potentially radioisotope contaminated surface from residual contamination on barrels shipped from Ontario Site.

Location: Painesville, Ohio

Date: 1997

Contaminant: Residues from extraction of uranium from pitchblende.

Regulatory Setting: State of Ohio, FUSRAP follows CERCLA procedures

Problem or Objectives: Characterize extent and type of contamination.

ESC Results: 52 acre site was successfully characterized in four weeks of field measurements. 


\section{TECHNOLOGY APPLICABILITY AND ALTERNATIVE TECHNOLOGIES}

\section{Technology Applicability}

The ESC approach is most appropriately used at the following types of sites:

- larger-scale projects, including CERCLA remedial investigations (RI/FS), and RCRA facility investigations (RFI, CMS).

- other contaminated sites where the ESC process can be reasonably expected to reduce time and cost of site characterization when compared with traditional approaches.

Generally, the ESC methodology may not be applicable at

- small petroleum release sites,

- Phase I real estate property transactions,

- sites where the contamination is limited to the near-surface and there is little likelihood for migration of contaminants into the ground water,

- sites where the cost of remedial action is less than the cost of characterization,

- sites where regulators may require long-term statistical monitoring of the site; a traditional approach involving grid-spaced monitoring wells may be more suitable,

- sites where existing statutes or regulations prohibit use of essential features of ESC.

\section{Competing Technologies}

Expedited Site Characterization is not the only streamlined characterization methodology currently in use. Scientists from industry, academia, and other federal laboratories have developed similar approaches.

- Baseline or traditional site characterization techniques:

Typically use a phased approach of data collection on a statistical basis or grid to develop a conceptual model of a site.

$\checkmark$ Each phase focuses on locating the contaminant plumes.

$\checkmark$ Each phase of the investigation follows a rigid pre-approved work plan and data are collected frequently by different subcontractors.

$\checkmark$ Data are analyzed and interpreted at the completion of each phase of work.

- The Observational Method is an investigative process developed and used in the 1920's to 1950's for geotechnical characterization of soils and geotechnical engineering design.

$\checkmark$ Characterization, design, and construction proceed hand-in-hand; as construction proceeds, observed changes in the soil system are used to modify the design.

$\checkmark$ A critical element of the method is an early assessment of most probable conditions.

- Application to remedial investigation or characterization stage focuses on determination of general site conditions and identification of most probable conditions and reasonable deviations as the basis for a flexible approach to remediation design.

- Adaptive Sampling and Analysis was developed and used by DoD to characterize to determine the nature, extent and level of contamination present at a site.

$\diamond$ This approach uses chemical analytical methods and on-site decision-making in the context of geostatistical models to guide sampling.

$\checkmark$ This approach is most applicable to characterization of near surface soil contamination.

- Data Quality Objectives (DQO) are a quality-management tool developed by the U.S. EPA, using a statistical approach to facilitate planning of environmental data collection.

$\checkmark$ This approach focuses on optimizing data collection and analysis so that the data are collected only to address the appropriate problems. 


\section{TECHNOLOGY APPLICABILITY AND ALTERNATIVES}

$\diamond \quad$ This approach differs from ESC in that

- An optimal fixed number of measurements in a statistical framework is used.

- Information from the first set of measurements is usually not used to refine the next set of measurements.

- Chemical measurement of the contaminants of concern is the focus in contrast to ESC where an integrated understanding of the geohydrologic framework is determined prior to plume delineation.

- SACM and SAFER Processes were developed by the U.S. EPA (Superfund Accelerated Cleanup Model) and the U.S. DOE (Streamlined Approach for Environmental Restoration). They are complimentary approaches for speeding up CERCLA RI/FS projects.

$\checkmark$ SAFER integrates DQO with the observational method.

$\checkmark$ ESC can be easily incorporated into the characterization portion of SAFER to provide a robust, integrated geohydrologic model of the site in a reduced time.

$\checkmark$ The use of ESC in SAFER and SACM would de-emphasize contingency planning due to the development of a robust and accurate site model during characterization.

\section{Patents Commercialization/Sponsor}

The ESC approach was originally developed by ANL, primarily for the USDA CCC for the characterization of former grain storage facilities. DOE through the CMST-CP funded development of an ASTM Guide titled "Guide for Expedited Site Characterization of Hazardous Waste Site" that is now provisional PS 85-96. The guide documents the implementation of ESC at DOE sites, and is an excellent introduction to common sense, cost-effective characterization at DOE sites. ANL and DOE have a trademark (QuickSite) on the application of ANL's ESC. 
Information in this section is summarized from a report prepared by Los Alamos National Laboratory (LANL) from a demonstration of ESC sponsored by DOE at the Zone 12 Pantex Plant in Texas (LA-UR97-2215). LANL was tasked to perform the cost analyses as an independent team for the DOE Office of Science and Technology. As part of this effort, LANL re-evaluated information presented in an earlier report evaluating the cost effectiveness of the application of ESC at DOE's Pantex Plant [LA-UR 96-2945). Although there are significant differences in the cost scenarios and conclusions presented by the authors in each of the studies, both studies showed a positive cost benefit from the application of ESC.

The main challenge in providing a robust cost analysis of ESC or any other technology is to establish a realistic cost scenario for both the baseline and innovative technology. For ESC, this is especially difficult, because the published case studies are speculative as to what outcomes would have been produced had the other approach been used.

The cost impact of ESC varies on a site-by-site basis. At some sites, the application of ESC will result in major cost savings relative to baseline methods, and at others, the cost of ESC will be comparable to baseline methods. The two major cost components of a completed site characterization study are costs associated with (1) drilling, sample collection, and sample analysis, and (2) labor.

\section{Cost Analysis: A Case Study at DOE's Pantex Plant: Zone 12}

At the DOE Pantex Plant in Texas, the distribution of contaminants and pathways for contaminant migration are complicated by the complex hydrogeology. The geological characteristics of the site include a perched aquifer at a depth of 250 feet and the 400-foot-thick Ogallala aquifer at a 450-foot depth. Prior to the ESC investigation, the U.S. Army Corps of Engineers (COE) had spent 2 years and \$2.1 million completing the first of a proposed four-phase comprehensive traditional characterization effort, that was scheduled to last 5 years and cost $\$ 11.9$ million.

Phase I of the COE effort included the drilling of 11 wells; the proposed additional phases called for installation of 43 additional wells. In contrast, the ESC investigation resulted in only four soil borings, one of which was later turned into a well, and nine cone penetrometer pushes. After the ESC team left the site, an additional 10 borings were made and 5 monitoring wells were installed to determine precisely what remediation efforts would be required to treat the contaminant plume.

Table 1 compares the number of penetrations estimated for completion of site characterization at Pantex. This table does not include the 11 monitoring wells drilled by the COE during Phase I. If the 11 Phase I wells are included, total penetrations for both methods would increase by 11 . The main significance of this table is that the ESC approach resulted in installation of significantly fewer monitoring wells.

\section{Table 1. Post-phase I Penetrations at the Pantex Plant}

\begin{tabular}{|ccc|}
\hline Type of Penetration & $\begin{array}{c}\text { ESC } \\
\text { (Actual) }\end{array}$ & $\begin{array}{c}\text { Traditional } \\
\text { (Planned) }\end{array}$ \\
\hline Borings & 13 & 0 \\
\hline CPT pushes & 9 & 0 \\
\hline Wells (perched aquifer) & 5 & 39 \\
\hline Wells (Ogallala) & 1 & 4 \\
\hline
\end{tabular}


Table 2 (below) shows a comparison in costs to characterize the Pantex site using either ESC or the traditional baseline method. The baseline assumed for this scenario includes the cost of the 11 wells done during Phase 1 characterization and an additional 43 wells that were proposed in the later phases of characterization.

For the ESC scenario, six Phase I wells were estimated and added to the actual ESC Phase II where only four soil borings, one of which was later turned into a well, and nine cone penetrometer pushes were completed. The ESC costs also include the additional 10 borings and the 5 monitoring wells that were installed after the ESC team left the site.

\section{Table 2. Characterization Costs at the Pantex Plant}

\begin{tabular}{|ccc|}
\hline & ESC & Traditional \\
\hline Preparation costs & $\$ 334,000$ & $\$ 150,000$ \\
\hline Cone penetrometer pushes (CPT) & 9 & 0 \\
\hline CPT total cost & $\$ 25,000$ & $\$ 0$ \\
\hline Phase I penetrations & 6 & 11 \\
\hline Other penetrations & 19 & 43 \\
\hline Total penetrations & 25 & 54 \\
\hline Average cost per penetration & $\$ 170,000$ & $\$ 192,000$ \\
\hline ESC Phase I cost & $\$ 461,000$ & - \\
\hline Overall penetration costs & $\$ 4.3$ million & $\$ 10.4$ million \\
\hline Other costs & - & $\$ 1.4$ million \\
\hline Total Costs & $\$ 5.1$ million & $\$ 11.9$ million \\
\hline
\end{tabular}

Preparation costs for the two methods are different, because the ESC approach requires a significant analytical effort by the ESC team to prepare a conceptual model before visiting the site. This effort includes evaluation of existing data, identification of data inconsistencies, data reprocessing and preparation of a data archive referenced to the coordinate grid.

The next set of costs includes drilling and CPT costs incurred in the ESC investigation. The ESC team made 9 CPT pushes at a total cost of $\$ 25,000$. Other penetrations by the ESC team include the 19 actual wells and soil borings and for the baseline method, the 43 proposed but never implemented wells. The cost per penetration for each approach are calculated from the actual costs incurred at the site, including labor for both the contractors and the science teams. The ESC costs per penetration are slightly lower because ESC made 13 soil borings but installed only 6 monitoring wells, while the traditional approach called for installation of 54 wells. The other cost data represents nonpenetration related costs incurred by the traditional approach including staff time.

\section{Conclusions and Comments}

- This hypothetical comparison predicts a 57\% savings in cost and a $40 \%$ reduction in time using ESC as compared to the traditional baseline method proposed at the Pantex Plant.

The above scenario represents a conservative estimate of cost savings that can be attributed to the ESC methodology in a specific DOE remediation case. The largest component of the cost savings resulted from a reduction in the number of subsurface penetrations and the number of samples collected for analysis.

- ESC Projects summarized in Section 3 of this report generally demonstrated that the ESC investigation almost always results in a cost savings in the drilling and sampling category. Additional long-term savings in ground water monitoring and analysis costs may be realized due to the reduced number of monitoring wells installed.

- The LANL reports do not show that the application of ESC provides a significant cost advantage over baseline methods in the labor category. However, this may not be a correct assumption for all ESC investigations. An average ESC team member, as defined is quite senior and higher paid than a traditional site characterization scientist but due to nature of the ESC process is employed for a shorter time. 


\section{COST}

- LANL determined that a significant cost savings from the implementation of ESC may result from a reduction in time to complete the characterization, however, the cost savings from these factors is difficult to quantify in a rigorous manner.

$\checkmark$ In DOE's Pantex Plant example, ESC delivers results in roughly half the time of its counterpart, two years ahead of the traditional method's schedule.

0 Generally, the ability to start remediation work sooner will result in an earlier remediation remedy. However, it it very difficult to quantify cost savings. In present value terms, this shortened budget profile can even be a negative to the cost savings calculations as earlier expenditures cost the government more in present-value dollars.

Regulatory policies, new technological approaches, and other factors will change over time with uncertain effects either increasing or decreasing future cleanup requirements and subsequent budgetary expenditures.

- A final advantage often projected for ESC is the improved characterization outcome. Better characterizations described in a number of the ESC projects have resulted in cleanups not needing to be done, and therefore, in major overall program cost reductions. 


\section{REGULATORY/POLICY ISSUES}

\section{Regulatory Considerations}

- Because ESC methodology explicitly includes regulatory interaction at the initiation of the project, concerns and issues important to the regulator will be addressed early in the process thus facilitating regulatory approval.

- Because regulatory agents are not legally bound by the recommendations of the ESC (or any other characterization) approach, time must be taken to be sure the regulators fully understand both the process and techniques to be employed.

- Normal drilling and sampling activities require that investigation derived wastes (IDW) (drilling fluids, cuttings, and equipment decontamination fluids) be handled according to RCRA. Emphasis on the use of non-intrusive methods and reduction of the number of subsurface penetrations should minimize amounts of IDW that are produced.

\section{Safety, Risks, Benefits and Community Reaction}

\section{Worker Safety}

- The risk to workers is minimized as the ESC approach incorporates use of non-invasive and minimally invasive techniques by using direct-push soil and ground water sampling equipment whenever practical. This results in a significant reduction in worker exposure as drill cuttings and drilling fluids are not used.

- The risk to workers is minimized because of reduced number of penetrations.

- The risk to workers is minimized due the reduction in the length of the remedial investigation.

\section{Community Reaction}

- Community involvement is explicit in the first stages of ESC. The community relations plan improves accountability to the public by helping the ESC project team identify the principal concerns of the stakeholders. The may help the ESC project team collect and present data that is responsive to stakeholders' needs.

- The emphasis on development and refinement of a clear conceptual model should improve community understanding and acceptance of the characterization process.

- The earlier initiation of remedial processes might lead to less community exposure to toxic compounds; this should be well received by the community. 


\section{SECTION 7}

\section{LESSONS LEARNED}

- A potential challenge for implementation of ESC is contractor bidding. Because ESC is a flexible tool, it is a challenge to prepare requests for proposals and contracts that can be managed effectively. It may be appropriate to prepare contracts on a per-penetration basis for each technique. Alternatively, minimum sampling requirements could be agreed upon with the regulatory agency and the contractors could bid on the minimum requirements with a negotiated additional per-well or per-penetration cost.

- The ESC process avoids a presumption that remedial action is required. However, remediation engineering experience should be incorporated into the process as soon as the need for remedial action is recognized.

- The selection of team members with appropriate qualifications, experience, and capabilities is critical to successful implementation of ESC. The maintenance of the same team from project initiation to closure is also vital but is often difficult to achieve at DOE sites due to the demands on senior technical personnel.

- The ESC process at a typical site requires single mobilizations of 2 to 4 weeks for Phase I, and a mobilization of similar length for Phase II. Various site specific factors including stakeholder relationships, site area and access, site geology and hydrology, and contaminant characteristics will affect the actual time and cost of an investigation. 


\section{APPENDIX A}

\section{REFERENCES}

1. DOE's Ten Year Plan (TYP) Cost Rollup by Category, Report ID D03, unpublished summary (March 1997).

2. "Guide for Expedited Site Characterization of Hazardous Waste Contaminated Sites," ASTM Committee D-18, D18.01.01 Task Group, Draft No: 6.0 (February 24, 1997).

3. Thomas P. Starke, "Cost Effectiveness Analysis of Expedited Site Characterization at the DOE Pantex Plant," Los Alamos National Laboratory Report LA-UR-96-2945 (1996).

4. McCreary, I and Booth, S. R., "Expedited Site Characterization", 1997, LA-UR 97-2215, Los Alamos National Laboratory, Los Alamos, NM.

5. Burton, J. C. et al., "Expedited Site Characterization: A Rapid, Cost-Effective Process for Preremedial Site Characterization", Superfund XIV, Vol. II, Hazardous Materials Research and Control Institute, Greenbelt, MD, 1993, pp. 809-826.

6. Starke, T.P., Purdy, C., Belencan, H., Ferguson, D., and Burton, J.C., "Expedited Site Characterization at the Pantex Plant", Proceedings of the ER-95 Conference, Denver, CO, 1995.

7. Burton, J.C., Walker, J.L., Aggarwal, P.K., and Meyer, W.T, Meyer, “Argonne's Expedited Site Characterization: An Integrated Approach to Cost- and Time-Effective Remedial Investigation," paper presented at 88th Annual Meeting, Air and Waste Management Association, 1995, 27 pages.

8. Burton, J.C., "Prioritization to Limit Sampling and Drilling in Site Investigations," Proceedings 1992 Federal Environmental Conference and Exhibition, Hazardous Material Control and Research Institute, Greenbelt, MD, 1992, pp. 242-251.

9. Starke, T.P., Kjartanson, B.H., Bevolo, A.J., and Purdy, C.B., "Expedited Site Characterization Coursebook," LA-UR-97-527, Los Alamos National Laboratory, Los Alamos, NM, 1997. 